\title{
Innovativeness of Industry Considering Organizational Slack and Cooperation
}

\author{
Júlio Francisco Blumetti Facó \\ UFABC \\ julio.faco@ufabc.edu.br \\ João Mário Csillag \\ joao.mario.csillag@fgv.br
}

\begin{abstract}
The purpose of this research study is to evaluate the influence of a company's cooperation resource availability on its innovativeness. 229 companies in the Manufacturing Industry segment were analyzed. Descriptive statistical analysis associated to regression analysis was used in order to achieve the research objective. Based on analysis of the data, it has become evident that the existence of organizational slack, as well as that of cooperation, positively influence a company's innovativeness, resulting in superior performance. Additionally, the quantitative research permitted the proposition of a predictive model which is applicable to the industry.
\end{abstract}

Keywords: Innovativeness, Organizational Slack, Cooperation.

\section{INTRODUCTION}

Hayes and Abernathy (1980) and also and Pavitt (2006), have long considered the act of innovation as one of the foundations essential for the success of a company. The importance of innovation is also justified by the action of three critical forces: intense international competition, the sophistication of the market and the rapid change of technologies. Any productive chain, ranging from those that are technically younger and dynamic to those that are more mature and have long life cycles, suffers the action of these three forces (Clark; Wheelright, 1993).

To the same effect, Tidd, Bessant and Pavitt (1997) claim that, although the competitive advantage may come from factors, such as the size or the ownership of resources, in the current model, authors observe the growth of the supremacy of organizations that are able to mobilize knowledge, technological capacity and experience to create new products, processes and services.

The fact that innovation is viewed as an element of competition among companies is not a recent trend.
Schumpeter (1982) and Solo (1951) already considered the act of innovating in organizations as a competitive attribute. Recently, Das and Joshi (2007) also observed that the capacity of a company to innovate may lead to a competitive business advantage. In fact, there is mounting evidence of these advantages for companies.

At the same time, companies need resources for their business activities, whether ones that transform or will be transformed. Organizational resources can be thought of in terms of people, equipment, technological resources, financial resources, and even patents or reputation, for example. Resources are, therefore, essential to companies, and the lack, excess or non-use of them affect the performance of a company's activities, such as those related to innovation.

Additionally, the constant search for measures of performance has been present in the agenda of organizations, for they are interested in knowing the developments, impacts and influences of everyday business decisions on the firm's performance. There is growing interest concerning the role of innovation in the performance of organizations. 
Thus, the purpose of this research is to evaluate the role of a company's cooperation and the availability of resources to it in relation to its capacity to innovate and improve performance. In order to do so, this research considered the company (firm) and the analysis of its capacity to innovate (organizational innovativeness) as the focal point of the study. Innovation does not happen per se; it involves a number of factors. One point that this study considers to be a key factor is the analysis of the slack or the availability of resources to a firm (organizational slack) and its relationship with the capacity of the organization to innovate. The company, on the other hand, as a unit of analysis, lies in a wider context, in a value chain that is represented in this study by two links: upstream, there are suppliers and downstream, customers. Just as with innovation, the chain context includes a number of dynamics and agents, and, in this research study, authors intend to evaluate the role of the cooperation of the links in the firm's capacity to innovate. Finally, all of these relationships need to be analyzed in terms of company performance. Thus, all of these parts will compose the constructs of the study, forming an amalgam of relationships.

\section{ORGANIZATIONAL INNOVATIVENESS}

The WordNet English dictionary (2009), available online from the University of Princeton, presents the following definition for innovativeness: "originality by virtue of introducing new ideas".

Understanding the introduction of new ideas to be the central point of the definition of innovativeness in the lexicon of the University of Princeton, it is possible to derive from it the concept of organizational innovativeness as being "an organization's tendency to engage in and support new ideas, novelty, experimentation, and creative processes that may result in new products, services, or technological processes" (Lumpkin; Dess, 1996, p.142). In practice, this concept reflects an important way in which organizations treat and direct new opportunities (Jambulingam; Kathuria; Doucette, 2005).

For the objectives of this research study, the expression, organizational innovativeness will be freely translated as the capacity of an organization to innovate or the capacity for organizational innovation, always maintaining a relationship between the terms organization and innovation.

It is worth remembering that innovation is not always necessarily lucrative, but is used by a company in response to, or in expectation of, a specific circumstance (Solo, 1951). The same author defends the claim that innovation is an element of competition for the company.

Besides the opinion that innovation is an instrument of competition for a company, Lundvall, Madsen and Kristensen (1997) suggest that innovation is also influenced by this competition. These same authors, while analyzing data collected in the 1990s on almost 2,000 Danish companies, observed that changes in the competitive environment of a company are related to changes in its capacity to innovate. According to the authors' own words, "firms experiencing an intensified competition are much more prone to develop new products" (Lundvall; Madsen; Kristensen, 1997, p.10). This was found because, when they analyzed the results based on a sample of 1,869 companies (from multiple sectors), they obtained a positive causal relationship between the changes in the intensity of competition of the environment and these companies' propensity to innovate, clearly showing, among other things, that innovation may be one of the best alternatives for reducing, in a consistent manner, the pressure on the profit generated by increased competition.

Another research project that treats innovation as a competitive alternative is the recent study conducted by Cho and Pucik (2005). These authors also characterize the capacity of a firm to promote innovation and creativity, while controlling the quality of their products and services, as agents of competitive advantage. The same authors defend the claim that the capacity of a firm to innovate can be considered an intangible resource that is difficult to imitate, combining the capacity to innovate with the theories of the Resource Based View (RBV).

It is worth noting that, according to the RBV theory, a sustainable competitive advantage results from characteristics, such as value, rarity, inimitability and use of the company's internal resources. (Barney, 1991; Grant, 1991; Peteraf, 1993) Under the aegis of the RBV, firms are no longer seen as merely a portfolio of products, but are now seen as a portfolio of resources, as can be observed in the works of Penrose (1955), Rubin (1973) and Wernerfelt (1984), offering a new perspective by which the financial results of the company are directly related to the resources it owns. Thus, the greater the resources and distinctive capabilities that a company possesses, the better its performance will be.

Based on this point of view, the firm represents more than an administrative unit, it "is also a combination of 
productive resources" (Penrose, 1995, p.61). The same Penrose also shows a relationship between her theoretical proposal and the innovative activities of a company. According to the author, "new productive services" are continually being created by the firm in any of the processes of operation and expansion (Penrose, 1995, p.121).

Therefore, RBV studies suggest that the organizations should possess resources that the competitors cannot easily copy, acquire or buy. As a result, the company that possesses these resources will obtain a competitive advantage. Current studies also point to an emphasis on the importance of the resources and capabilities related to innovation inside the companies (Hamel; Prahalad, 1994; Tidd; Bessant; Pavitt, 2005). In all of the studies mentioned, the resources and the company's capabilities for innovation are essential elements for the generation of innovations.

On the other hand, Michael Porter's line of generic strategies (1986) related to cost, differentiation or focus, has also attracted the attention of researchers, not only from the area of strategy, but also from more technical areas, such as marketing and operations management (DAS; JOSHI, 2007). From among these generic strategies, the company must opt for the one which best serves it. The distinctive characteristic of this approach, according to Tidd, Bessant and Pavitt (2006), is the comprehension of the competitive environment in which the company operates. However, under this approach, little attention is dedicated to the internal resources and capabilities of a company related to its strategic option, unlike the RBV approach. Based on various studies on operations management, Das and Joshi (2007) conclude that innovation must also be included as a competitive priority in the organizations, and that the quality, flexibility and capacity to innovate of a firm are all consistent operational objectives with strategies guided by differentiation.

\subsection{Cooperation as a driver for innovation}

Related to the perspective of cooperation among companies, Chen and Paulraj (2004, p.136) observed that the context of value chain represents "one of the most important paradigms in business management of the present day," because it recognizes that individual businesses no longer compete alone as anonymous entities, but as value chains and networks.

Based on the proposal of value networks, Ronde and Hussler (2004) analyzed data from 94 regions in
France where manufacturing companies (and their respective value networks ) are established. In their conclusions, these authors verified the importance of the region for the explanation of innovative activities of the manufacturing companies, and also validated their hypothesis of positive influence of the value chains and of cooperation among organizations on the development of innovations. Nevertheless, Ronde and Hussler (2004) suggest a deepening of the study of these network relationships at company level (in a less aggregated way than that of a value network). The same authors also propose a refinement of the comprehension of how knowledge flows through companies.

Still in the context of value chains and networks, some works sought to analyze the sources of innovations, or even innovative stimulus external to companies. Perhaps one of the most relevant works of comprehension of these sources of innovation would be the research proposed by Eric Von Hippel (1988). In his work of more than a decade, Hippel (1988) identified three distinct sources of innovation: users, suppliers and manufacturing companies. More recently, (Hippel, 2007, p. 28) has considered a "user-driven innovation and knowledge diffusion" line as the central object of his studies concerning the innovation sources of companies. An important point must be duly noted: Since 2005, the government of Denmark has financed and maintained a research center in which the focus is innovation centered on the user ${ }^{1}$, based on the proposals of Von Hippel. Whether because of his seminal work in 1988 or because of more recent refinements of his line of research, Hippel's proposal $(1988,2007)$ emphasizes communication and exchange of knowledge between the company and the supplier and, especially between the company and the user, as the key for better innovations.

From the same perspective of chain and of the company-supplier relationship as a source of innovation, Geffen and Rothenberg (2000) studied some assembly plants in the USA. These authors found evidence that reinforced the importance of suppliers as sources of knowledge and know-how in the implementation of innovations in the sample studied.

Another research study that also made apparent the influence of the links of the chain on innovations in companies was conducted by AbecassisMoedas (2006), who investigated the relationships between clothing manufacturers and distributors in

\footnotetext{
${ }^{1}$ Additional information: http://duci.dk/
} 
the clothing and apparel chain in the USA, the UK and France. After 50 semi-structured face-to-face interviews, the author observed that the strategy of cooperation to integrate the design, the making and the distribution of garments resulted in innovations, both of process and of product, for the productive chain as a whole.

Thus, just like Jensen et al (2007), authors observe that the innovation of the chain occurs by means of the interaction with clients as well as with suppliers. Both are key links in this mechanism of innovation and, therefore, objects of study in this research.

\section{ORGANIZATIONAL SLACK}

A parallel of the theme of organizational slack can be drawn using the theories of RBV as a background. The theories of RBV, briefly described in previous topics, are particularly interesting to this research, for they propose a view of the company as a combination of resources. Since the purpose of this topic is to elaborate with regard to the availability of resources to a company (or organizational slack, as this study refers to it), parallels to the RBV will be drawn whenever necessary.

Penrose (1995), proposed that:

\begin{abstract}
"Non-used productive services proceeding from existing resources [in the companies] constitute a "waste", which is sometimes inevitable (meaning that it may not be worth it to use them), but, at the same time, represent "free" services, which, if able to be used productively, are capable of bringing about a competitive advantage to the firm that retains them."(Penrose, 1995, p.121)
\end{abstract}

This slack or availability of resources, while it can potentialize the competitive position of the firm, it is also seen as an impediment to the organizational performance and to the innovation activities in organizations (Herold; Jayaraman; Narayanaswamy, 2006; Love; Nohria, 2005). This happens because slack at firm level may also reflect some type of inefficiency (Sawhney, 2006; Tan; Peng, 2003; Marucheck; McClealland, 1992; Sharfman et al, 1988, Voss; Sirdeshmukh; Voss, 2008).

Marucheck and McClealland (1992) treat organizational slack and the idle capacity of a firm as synonyms, recalling that both are associated to costs in the company. To these authors, idle capacity is a source of costs for an organization, which may also occur in the form of idle employees, loss or reduction of productivity, or even, to quote the words of the authors themselves, "reduced employee morale"(p.28).

Regarding people, Love and Nohria (2005) researched the reduction of organizational slack - from the viewpoint of downsizing - and its relationship to the performance of a company. These authors proposed that the understanding of the amplitude of the concept of slack was not restricted to the dimension of people (human resources), but rather encompassed various types of excess resources in the company, which could be in the form of retained profits (not used), stock, working capital and people. These same authors also found evidence in academic literature that organizational slack can facilitate the adaptation, innovation, creativity and risk taking of an organization, providing the necessary resources for these activities.

Related to a company's capacity to innovate, Penrose (1995, p.144) makes it clear that the non-used resources "constitute to the entrepreneurial firm simultaneously a challenge to innovate, an incentive to expand and a source of competitive advantage." Also, according to the author, these non-used resources facilitate the introduction of new combinations of resources in the company (which she called innovations). These new combinations may be combinations of services for the generation of new products, new processes or new forms of organization.

The conclusions of Herold, Jayaraman and Narayanaswamy (2006) emerge in a complementary way. According to these authors, the slack (or availability) of resources of an organization "is a possible source of financing for innovation" (Herold; Jayaraman; Narayanaswamy, 2006, p.373). This source consists of resources that are available to the company and go beyond those necessary to meet the immediate needs of the business and to conduct its routine activities, programs and objectives.

Rosner (1968) proposes a broad view of organizational slack. To Rosner (1968), this slack allows companies to: acquire innovation; absorb mistakes; explore new ideas beyond the current needs; and bear the costs of developments and implementation of innovations.

Tracing a parallel to the theory of RBV, Bourgeois (1981) classified this organizational slack as a type of resource that the managers have in their hands to help them in their everyday decisions (Bourgeois, 1981, p.31). In this sense, organizational slack is a 
resource that makes it possible for the company to adjust to great changes in the external environment with a smaller internal impact, as well as to experiment with new postures in relation to the environment, whether by the introduction of new products or by innovations in the business (Bourgeois, 1981).

In view of all that has been mentioned, the theme of organizational slack can be seen under a prism that, at the same time, promotes an incentive for innovative opportunities, and is also a form of waste and expense that negatively affect the company's results.

Trying to accommodate the positive and negative views of this prism, Bourgeois (1981), in his extensive study about organizational slack, proposed the existence of a curvilinear relationship between the organizational slack of resources and its performance in the company.

Nohria and Gulati (1996), Tan and Peng (2003), and Herold, Jayaraman and Narayanaswamy (2006) started out from the theory proposed by Bourgeois (1981), associated it to other evidence and proposed a relationship between organizational slack and innovation in companies. Each relationship had its own characteristics and was based on empirical tests, proxies of innovation and organizational slack, which will be described in the following two topics.

However, all of the research presented or consulted here concerning the study of organizational slack and its relationship to innovation in companies did not point out or gave little emphasis to the capacity of innovation as the agent preceding innovation per se. Therefore, the exploratory analysis of this relationship between organizational slack and the capacity of innovation of a firm is an opportunity for research, as explored in this study.

\section{METHODOLOGY}

The use of statistical methods and surveys is increasingly frequent in the research involving aspects related to companies Boyer and Pagell (2000) as well as Craighead and Meredith (2008), while analyzing in retrospect the research studies in the field of business and, particularly, operations - which is where this study is situated - observed, in recent years, a significant growth in the use of research based on great quantities of data (hundreds of observations) collected directly in the companies.
According to Hair et al. (2005), any researcher who examines only the relationships between two variables and avoids multivariate analysis is ignoring powerful tools that can supply useful information for a better understanding of the complex phenomena of the environment of organizations.

Hair et al (2005) and Malhotra (2001) emphasize the fact that the multivariate methods of analysis allow researchers to simultaneously analyze multiple measurements of each object of investigation.

Thus, in this research, for the quantitative part, the authors use descriptive statistical analysis associated to regression analysis. Hair et al. (2005) assert that regression is an appropriate method of analysis when the research topic involves a single dependent variable considered related to two or more independent variables (which will be presented in detail further ahead) The objective of this analysis is to predict the changes in the dependent variable in response to the changes in the independent variables.

In a similar manner, Malhotra (2001) classified regression analysis as a flexible process capable of supplying the researcher with understanding of relationships between independent variables and one dependent variable. However, this same author reminds us that, though the independent variables may explain the variation of the dependent variable, this does not signify a causal relationship. The objective of regression analysis is the nature and degree of association among variables (Malhotra, 2001; Hair et al, 2005).

\subsection{Sample of the Survey of Quantitative Data}

The secondary data base used in this research was the Sondagem FIESP das Necessidades de Inovação na Indústria Paulista - SNIIP [FIESP Survey of the Needs for Innovation in São Paulo Industry], which, though not widely made public, is a base that has administrative, financial and operational information found in a sample of companies of different sizes and industrial sectors in São Paulo State, and, therefore, paints a very rich portrait of Paulista ${ }^{2}$ industry. Considering the fact that the availability of reliable data is one of the greatest difficulties for the conduction of empirical researches, authors must point out the importance and relevance of this base, even more so in a country like Brazil, which still has

2 Paulista - belonging to or coming from São Paulo State , Brazil. 
a shortage of information, such as that found by the FIESP survey.

Conducted by the Federação das Indústrias do Estado de São Paulo - FIESP [Federation of São Paulo State Industries], SNIIP was coordinated by the Departamento de Competitividade e Tecnologia - DECOMTEC [Department of Competitiveness and Technology] , a department of FIESP. It was conducted with companies in São Paulo State in May 2007, and included organizations of different sizes and industrial sectors (sectors that are detailed in the attachment to this research).

The motivation and objective of the survey conducted by FIESP was to verify the dynamics of Paulista industrial innovation, both in terms of the process itself, as well as the environment and the conditioning factors in the companies when they carried out innovative activities.

This study analyzed 229 companies of the Manufacturing Industry segment that were included in the FIESP Survey.

This sample is not probabilistic, therefore, the results do not have external value and the conclusions cannot be generalized; however, the sample is reasonably large enough to be considered a contribution to company administration knowledge, and, more specifically, to operations management and to the theme of innovation.

\subsection{Sample Grouping}

Based on the OECD classification, Smith (2006) proposed that studies involving the measurement of innovation be divided into 4 categories, according to their intensity of activities of research and development (p.157):

a. High-technology industries (e.g. aviation, pharmaceuticals , telecommunications equipment, electro-medical):

b. Medium-high-technology industries (e.g. electrical equipment, vehicles, chemical industry);

c. Medium-low-technology industries (e.g. coking, petroleum refining, rubber and plastic products, manufacturing of metal products);

d. Low-technology industries (e.g. production of wood, pulp, paper, recycling, products for printing and publication, food products, textile products).

For the purpose of this research and with the intention of facilitating the analyses and conclusions, one starting point was the classification proposed by the OECD and by Smith (2006), with the grouping of the industries of medium-high and low-medium technologies to form another group called medium technology.

Thus, the three groupings that this research used concerning technological intensity are: High Technology: products of high complexity; Medium Technology: products of medium-high and medium-low complexity; and Low Technology: products of low complexity.

\section{Analysis of the Database}

The objective of this topic is to present the results of the evaluation of the data analysis for the identification of factors that give rise to the innovation capacity of companies.

Based on the survey conducted by FIESP in 229 companies from 26 different manufacturing industry segments, the authors identified the measurements (questions of the questionnaire) that had any connection to the constructs proposed in this research. A brief description of how each measurement was identified is presented in sections 5.1 to 5.5. Due to the restriction in the size of the sample, and in order to accommodate the requisites of the multivariate analysis chosen (regression), it was necessary to conduct detailed analysis of the impact of all of these measurements. This lead to the selection - and aggregation - of those that best explained the performance of the firm. On the other hand, this decision to reduce the use of measurements entails models that are more parsimonious, yet still very rich in information and analytical developments, as will be explained in more detail in the next topic.

\subsection{Performance Measurement}

In regression, the performance of the company corresponds to the response variable and originated based on the measurement: "The investments in innovative activities generate more costs than revenue for my company", from the questionnaire in which the alternatives for the response were a 6-point Likert scale ranging from strongly disagree to strongly agree.

The alternatives related to the levels of agreement (strongly agree, somewhat agree, etc.) were aggregated into only two levels: agree or disagree. The purpose of this procedure was to allow better analysis, taking into consideration the size of the sample 
that reflects in terms of fewer parameters to estimate. The companies were then classified into two categories of responses.

From this analysis, authors were able to classify a respondent company into one of the two categories. Thus, because of the nature of the response variable, the need to verify the association between the performance (with two categories) and the various characteristics of the companies requires the multinomial regression model, particularly the logistics regression model (Hair et al, 2005).

The multinomial regression model permits the evaluation of diverse impacts of each factor (or company characteristic) by type (responses) of performance.
Therefore, the response variable is made up of two categories, dividing the companies - to use the names given in this research - into Innovative (or efficient innovators) and non-innovative (or inefficient innovators). This measurement reflects the performance construct of this research. Table 1 shows the division of the companies according to these two categories. It is worth noting that the number of observations, a maximum of 229 not taking into account the exclusion of those that did not answer some of the questions, limits the use of the number of variables in the model, as well as the number of response categories for the non-quantitative variables considered in the analysis (Hair et al, 2005).

Table 1: Performance Variable

\begin{tabular}{|l|c|c|}
\hline Category of the company & N & $\mathbf{\%}$ \\
\hline Non-innovative (or inefficient in innovation) & 104 & 45.4 \\
Innovative & 125 & 54.6 \\
Total & $\mathbf{2 2 9}$ & 100.0 \\
\hline
\end{tabular}

Source: Author based on database/ FIESP.

The variables selected to make up the combination of factors that influence the performance of the company are the same measurements proposed previously in Part 1 (organizational slack, the capacity of a company to innovate, and cooperation). These measurements are presented below.

\subsection{Cooperation Measurement}

For the cooperation construct, two measurements were able to be initially identified in the database. These measurements, which in some way explain or help to explain this construct are given by the questions: "In the last two years, has your company had any institution or agent external to the company acting as an influencer, decider or specifier in innovations?" and "When conducting innovations, has your company ever used, hired, formed a partnership with an external institution or agent offering technological services in the last two years? The answers were yes or no. These measurements were constructed in such a way that, if a company responded affirmatively to the first or second question, or to both, this indicator presented value 1 . If the company did not respond affirmatively to either of these questions, the indicator presented value 0 .
To identify the external influence in product innovations, the following response parameters were considered: P\&D, Design, Product Innovations and Industrial Design. For the indicators of management and process innovations, the items, management innovation and process innovation were considered respectively, for both questions. Therefore, this measurement makes use of an association of these measurements.

\subsection{Slack Measurement}

For the resource slack construct, some measurements were able to be initially identified in the database and, after the application of regression, the one that showed the best adherence was the measurement used: "My company needs qualified human resources, but does not have the financial resources to absorb them in the company," in which the response alternatives were a 6-point Likert scale ranging from strongly disagree to strongly agree.

\subsection{Innovation Capacity Measurement}

In an analogous way, for the capacity of the company to innovate (innovativeness) construct, the 
measurement selected was "My company possesses long-term innovation management in processes and products," in which the response alternatives were a 6-point Likert scale ranging from strongly disagree to strongly agree.

\subsection{Control Measurements: Influence of the Envi- ronment}

- Initially, the three variables selected that could in some way influence the results were:

- Size: operationalized by two measurements - one of them being the number of employees and the other, the company's revenue.

- Sector in which the company acts.

- External environment favorable to innovation.

- Concerning the measurement of the size of the company, the number of employees was considered in the analysis with four range categories: up to 29 employees, 30 to 99 employees, 100 to 249 employees and, finally, 250 employees or more.

- For the classification of the sector in which the company acted, and with the purpose of maintaining a strict relationship with the division already presented in the methodology (three levels according to the technological intensity of the sector), this variable was grouped in the same three categories proposed previously: high, medium and low technological intensity.

- Finally, the measurement "In the next few years, my company intends to greatly increase the investments in innovative activities as a primordial factor in the growth of our competitiveness," also had its categories related to the levels of agreement (strongly agree, somewhat agree, etc.) grouped into only two levels: Agree and Disagree, which were named 'favorable external environment' and 'unfavorable external environment' respectively. This measurement reflects the business environment variable.

Table 2 presents a summary of the descriptive analysis of the control variables.

Table 2: Sample According to Control Variables

\begin{tabular}{|l|c|}
\hline Number of Employees & N \\
\hline Up to 29 & 63 \\
30 to 99 & 91 \\
100 to 249 & 38 \\
250 and over & 34 \\
Total & $\mathbf{2 2 6}$ \\
\hline Technological Intensity & $\mathbf{N}$ \\
\hline Low & 78 \\
Medium & 113 \\
High & 28 \\
Total & $\mathbf{2 1 9}$ \\
\hline Revenue Range of the Company (US\$ 1,000 ) & $\mathbf{N}$ \\
\hline$<705$ & 46 \\
$>705$ and $<6,175$ & 100 \\
$>6,175$ and $<35,300$ & 51 \\
$>35,300$ & 25 \\
Total & $\mathbf{2 2 2}$ \\
\hline External Environment Favorable to Innovation & $\mathbf{N}$ \\
\hline Yes & 168 \\
No & 37 \\
Total & $\mathbf{2 0 5}$ \\
\hline
\end{tabular}

Note $1:$ US\$ $1.00=\mathrm{R} \$ 1.70$

Note 2 : Some data are missing links

Source: Author based on database/ FIESP. 
Concerning the measurement of the size of the company, the range of the number of employees was considered in the analysis with four categories: up to 29 employees, 30 to 99 employees, 100 to 249 employees, and 250 employees or more.

For the classification of the sector in which the company acted, and with the purpose of maintaining a strict relationship with the division already presented in the methodology (three levels according to the technological intensity of the sector), this variable was grouped in the same three categories proposed previously: high, medium and low technological intensity.

Finally, the measurement "In the next few years, my company intends to greatly increase the investments in innovative activities as a primordial factor in the growth of our competitiveness," also had its categories related to the levels of agreement (Strongly agree, Somewhat agree, etc.) grouped into two levels only: Agree and Disagree, which were named 'favorable external environment' and 'unfavorable external environment' respectively. This measurement reflects the business environment variable.

Before proceeding with the application of regression, it is important to justify the non-use of Cronbach's alpha in the following analyses. According to Malhotra (2001), Cronbach's alpha is much used to evaluate if a group of questions/measurements are in effect measuring the same factor, and could, therefore, be grouped into a new measurement (or construct). The alpha analysis was not used in this research for two main reasons. First, the objective was to evaluate the influence of each independent variable both individually as well as in the regression combination for the response variable. Secondly, the authors did not use it because it was not the intention to create a new measurement, since, in this study, when opportune, they only combined the responses to the questionnaire in a logical manner.

\subsection{The Application of Regression to the Database}

Considering the type of response variable (categorical), the authors opted for a model of logistics regression. Different from a model of simple regression, in which the response variable takes on continuous values on a number scale, in the logistics regression model, the response variable identifies the state of the company, which, in the present study, can be: innovative or non-innovative.
In other words, the response variable corresponds to the classification of the company into one of two categories. The model to be adjusted estimates the probability of a company belonging to one of these two groups based on the combination of independent variables (capacity of innovation, resource slack and cooperation).

With $p_{i}$ as the probability of a company being classified into the category "innovative" of the performance variable, then the logistics regression is given by the equation:

$$
\begin{aligned}
& \log \left(\frac{p_{i}}{1-p_{i}}\right)=\mathrm{b}_{0}+\mathrm{b}_{1} X_{1}+\ldots+\mathrm{b}_{k} X_{k} \\
& p_{i}=\frac{1}{1+e^{-\left(\mathrm{b}_{0}+\mathrm{b}_{1} X_{1}+\ldots+\mathrm{b}_{k} X_{k}\right)}}
\end{aligned}
$$

and

Where the $X s$ correspond to the independent variables.

The function $\log \left(\frac{p_{i}}{1-p_{i}}\right)$ is also known as logit
(Hair et al, 2005).

This model allows for the analysis of the results by means of comparison of the influence on a variable for the classification of a company into the category of innovative or non-innovative. This analysis uses the estimated coefficients for each independent variable (exponing them) in the form of reason of chances. The chance corresponds to the quotient between the probability of a company being innovative and its complement (not being innovative).

Similar to the stepwise analysis of regression, initially, the adjustment of the whole model was made, identifying the independent variables that do not contribute (have little influence) to the modeling and, consequently, can be removed from the model. This process is repeated until a parsimonious model is obtained with an adjustment that is considered adequate. For the adjustment of the model, a level of significance of around $5 \%$ was used (to maintain one of the independent variables in the model).

In order to verify the adequacy or adjustment of the logistics regression model, the Hosmer-Lemeshow test was conducted, and the proportion of cases where the model estimates greater probability for the category in which the company is in effect classified was calculated. 
In Table 3, the variables of the model obtained the following $p$-value:

- Cooperation: $(\mathrm{p}=0.0026)$;

- Innovativeness: $(\mathrm{p}=0.0349)$;

- Slack: ( $p=0.0511)$. This measurement was kept in the model despite presenting a descriptive level with a p-value greater than 0.05 , since this value was considered to be very close to the level of significance established (5\%).
- Environment: $(\mathrm{p}=0.0008)$;

A notable point in Table 3 is the presence of the control variable (EA). From there it , natural questioning, which occurs based on its analysis in the Table, concerns the behavior of the model if the environment variable were removed. The fact is that the removal of the variable EA would imply a reduction in the degree of adjustment of the model (since Table 3 represents the model that best explains the performance of the company).

Table 3: Estimates of the Coefficients of the Logistics Regression Model applied to the Database

\begin{tabular}{|c|c|c|c|c|c|c|c|}
\hline Variables of the Model and Characteristics & Coefficient & $\begin{array}{l}\text { Standard } \\
\text { Error }\end{array}$ & $\begin{array}{c}\text { Wald } \\
\text { Statistic }\end{array}$ & $g f$ & $\mathrm{p}$ & $\begin{array}{c}\text { Reason } \\
\text { of } \\
\text { Chance }\end{array}$ & $\begin{array}{c}\text { Confidence } \\
\text { Interval of } 95 \%\end{array}$ \\
\hline \multicolumn{8}{|l|}{$X_{1}-$ Coop } \\
\hline Yes & 0.95 & 0.32 & 9.04 & 1 & 0.0026 & 2.58 & {$[1.39 ; 4.79]$} \\
\hline No (Reference Category) & - & & & & & 1 & \\
\hline \multicolumn{8}{|l|}{$X_{2}-E A$} \\
\hline Yes & 1.43 & 0.42 & 11.25 & 1 & 0.0008 & 4.16 & {$[1.81 ; 9.56]$} \\
\hline No (Reference Category) & - & & & & & 1 & \\
\hline \multicolumn{8}{|l|}{$\mathrm{X}_{3}-\mathrm{S}$} \\
\hline Yes & -0.61 & 0.32 & 3.51 & 1 & 0.0511 & 0.54 & {$[0.29 ; 1.03]$} \\
\hline No (Reference Category) & - & & & & & 1 & \\
\hline \multicolumn{8}{|l|}{$\mathrm{X}_{4}-\mathrm{Cl}$} \\
\hline Yes & 0.71 & 0.34 & 4.45 & 1 & 0.0349 & 2.03 & {$[1.05 ; 3.92]$} \\
\hline No (Reference Category) & - & & & & & 1 & \\
\hline $\mathrm{b}_{0}$ - Constant & -1.13 & 0.49 & 5.32 & 1 & 0.0211 & 0.32 & \\
\hline
\end{tabular}

Note 1: The Wald statistic supplies the statistical significance for each estimated coefficient, and it is information of the same importance as the independent variable in the model. This statistic has a Qui-squared distribution of probabilities (Hair et al, 2005).

Source: Prepared by an author

On the other hand, the authors also observe that environment - as control variable (EA) - is one of the "most important" in the model, with greater Wald statistics. Furthermore, the influence of the EA variable on the dependent variable is significant, because, when observing the reason of chance associated to this variable, the authors clearly see the greatest chances in Table 3 of a company responding affirmatively to this question about its performance. Details of this and other interpretations of the variables of the study based on Table 3 are found below:

- The performance of a company in the sample is increased when there is cooperation. The authors find this because, for the companies that in some way cooperate, there is 2.58 times more chance for them to show a positive result in their perfor- mance than those that do not cooperate, when keeping the other characteristics of the model controlled;

- The smaller the company's slack or availability of resources, the more the performance of a company in the sample is diminished. This fact is clearly shown in the Table, because, the chance for positive performance of the company is $46 \%$ less for organizations that do not possess availability of resources than for those that possess available resources, when keeping the other characteristics of the model controlled;

- The capacity of a company in the sample to innovate positively influences its performance. The authors find this because, for the companies that stimulate or develop their capacity to innovate, there is two times more chance (2.03) that they 
will show a positive result in their performance, when keeping the other characteristics of the model controlled;

- Both the size of the organization and the sector in which it acts did not show significant influence on the performance. Only the variable of control related to the environment showed significant influence on the performance of the company. This way, a favorable environment external to the companies (of the sample) raised their chance of positive performance by 4.2 times, when keeping the other characteristics of the model controlled;

From the regression model obtained, the companies can be classified into one of two categories based on their performance: innovative and non-innovative, as already shown above. From the probability esti- mated by the regression model, it is possible to determine (choose) a cut point from which the company is allocated to one group or the other. The choice of this probability cut point is made based on the result of the application of a methodology called the ROC curve (receiver operating curve). Two possibilities are considered to determine the point of:

- sensibility sensitivity which corresponds to the proportion of innovative companies correctly classified via the model as innovative; and,

- specificity which corresponds to the proportion of non-innovative companies correctly classified via the model as non-innovative.

he final model is given by the equation:

$$
\begin{aligned}
& \log \left(\frac{\hat{p}_{i}}{1-\hat{p}_{i}}\right)=\beta_{0}+\beta_{1} X_{1}+\beta_{2} X_{2}+\beta_{3} X_{3}+\beta_{4} X_{4} \\
& \log \left(\frac{\hat{p}_{i}}{1-\hat{p}_{i}}\right)=-1,13+0,95 X_{1}+1,43 X_{2}-0,61 X_{3}+0,71 X_{4} \\
& \left.\hat{p}_{i}=\frac{1}{1+e^{-\left(-1,13+0,95 X_{1}+1,43 X_{2}-0,61 X_{3}+0,71 X_{4}\right)}} \text { (Eq. } 1\right)
\end{aligned}
$$

For this model (Eq. 1), the Hosmer-Lemeshow test indicated adequacy $\left(\chi_{7}^{2}=7,77 ; \mathrm{p}=0,353\right)$.

From these analyses, the authors are able to obtain a predictive model concerning the performance of the company (innovative or non-innovative), in which the cut point can be determined by the ROC curve (Chart 1).

From the ROC curve ( Chart1), the authors determined the cut point at 0.59 at which they classified as innovative all of the companies whose estimated probabilities (using Eq. 1) were higher than the value of 0.59 , obtaining a global hit rate of $69.7 \%$ with sensivity $74 \%$ and specificity $63 \%$.

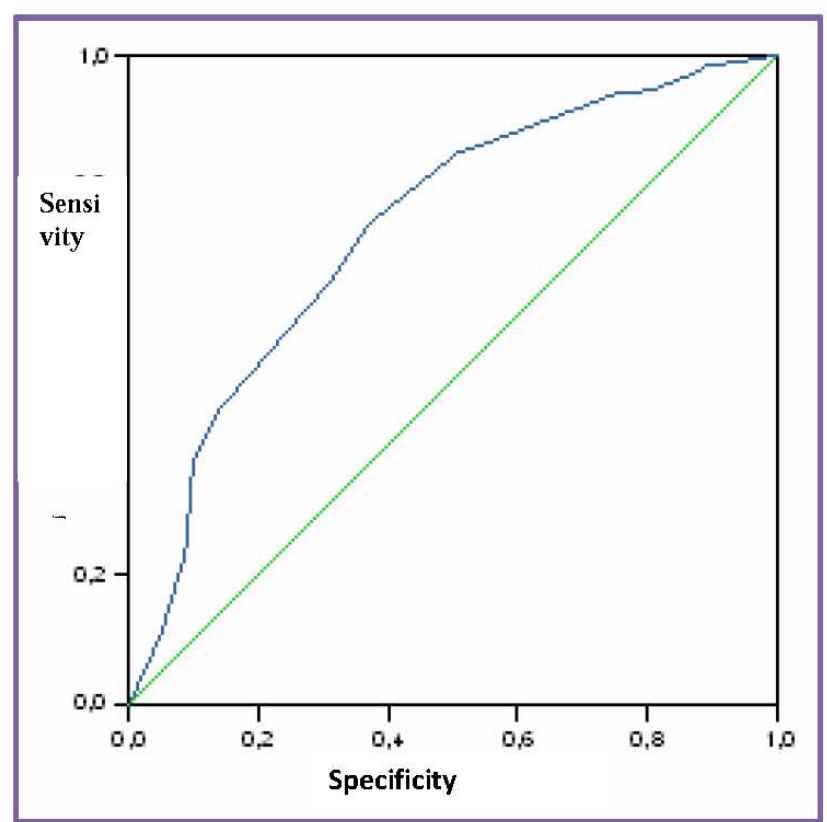

Chart 1: ROC Curve 


\section{CONCLUSION}

Based on the analysis of the data, it is clear that the existence of organizational slack as well as that of cooperation positively influence the company's capacity to innovate, resulting in superior performance.

Additionally, the quantitative research allowed for the proposition of a predictive model applicable to the industry, according to the database, involving all of the study variables: organizational innovativeness (CI); organizational slack (S); cooperation (Coop); performance (P); and, also, included a variable for environment (EA). The Model is presented in Equation 2, below:

$$
\hat{p}_{i}=\frac{1}{1+e^{-(-1,13+0,95 C o o p+1,43 E A-0,61 S+0,71 C I)}} \text { (Eq. 2) }
$$

From the ROC Curve, explained in previous topics, the authors determined the cut point to be 0.59 , for which all the companies whose estimated probabilities (using Eq. 2) exceeded the value of 0.59 , were classified as innovative.

Also, based on Equation 2, the authors are able to observe that all of the constructs contribute to the performance of the company and could be the subject of future studies.

The results and conclusions of this research cannot be generalized, since the sample is not probabilistic. However, the size and the extension of the database made it of interest to the investigation, thus contributing to the discussion about the innovation capacity of companies. However, Equation 2 could be tested and used in further works as references .

Finally, this study sought to contribute to the increase in the empirical studies with Brazilian companies under the aegis of operations and innovation.

\section{BIBLIOGRAPHICAL REFERENCES}

ABECASSIS-MOEDAS, C. Integrating Design and Retail in the Clothing Value Chain: An empirical study of the organization of design. International Journal of Operations \& Production Management, vol.26, p.412-428, 2006.

BARNEY, J. Firm Resources and Sustained Competitive Advantage. Journal of Management, vol 17, p. 99-120, 1991.

BOURGEOIS, L.J. On The Measurement of Organizational Slack. Academy of Management Review, vol.6. n.1 p.29-39, 1981.

BOYER, K.K.; PAGELL, M. Measurement issues in empirical research: improving measures of operations strategy and advanced manufacturing technology. Journal of Operations Management, vol.18, p.361-374, 2000.
CHEN, I.J.; PAULRAJ, A. Towards a Theory of Supply Chain Management: The constructs and measurements. Journal of Operations Management. vol.22, p.119-150, 2004.

CHO, H.; PUCIK, V. Relationship between Innovativeness, Quality, Growth, profitability, and Market Value. Strategic Management Journal, col. 26, p.555-575, 2005.

CLARK, K. B.; WHEELWRIGHT, S.C. Managing New Product and Process Development. New York: The Free Press, 1993.

CRAIGHEAD, C.W.; MEREDITH, J. Operations management research: evolution and alternative future paths. International Journal of Operations \& Production Management, vol.28, p.710-726, 2008

DAS, S.R.; JOSHI, M.P. Process innovativeness in technology services organizations: Roles of differentiation strategy, operational autonomy and risk-taking propensity. Journal of Operations Management, vol. 25, p.643-660, 2007.

GEFFEN, C.A.; ROTHENBERG, S. Suppliers and Environmental Process: The automotive paint process. International Journal of Operations \& Production Management, vol.20, p.166-186, 2000.

GRANT, R. M. The Resource-Based Theory of Competitive Advantage: Implications for Strategy Formulation. California Management Review, v33, . 3, p114-135, 1991.

HAIR, J.F.; ANDERSON, R.E.; TATHAM, R.L.; BLACK, W.C. Análise Multivariada de Dados (Multivariate Analysis of Data) 5ed, Porto Alegre: Bookman, 2005.

HAMEL, G.; PRAHALAD, C. K. Competing For The Future. Boston: HBS, 1994.

HAYES, R.H.; ABERNATHY, W.J. Managing our way to Economic Decline. Harvard Business Review, pp.67-77, July/August, 1980.

HEROLD, D.M.; JAYARAMAN, N.; NARAYANASWAMY, C.R. What is the Relationship between Organizational Slack and Innovation? Journal of Managerial Issues, vol.28, p.372-392, Fall 2006.

HIPPEL, E.V. An Emerging Hotbed of User-Centered Innovation. In: The HBR Bre akthrough Ideas for 2007. Copresented by Harvard Business Review and the World Economic Forum, p.20-54, February, 2007.

HIPPEL, E.V. The Sources of Innovation. Oxford University Press, 1988.

JAMBULINGAM, T.; KATHURIA, R.; DOUCETTE, W.R. Entrepreneurial Orientation as a Basis for Classification within a Service Industry: The case of retail pharmacy industry. Journal of Operations Management, vol.23, p.23-24, 2005.

JENSEN, M.B.; JOHSON, B.; LORENZ, E.; LUNDVALL, B.A. Forms of Knowledge and Modes of Innovation. Research Policy, 2007.

LOVE, E.G.; NOHRIA, N. Reducing Slack: The performance consequences of downsizing by large industrial firms. Strategic Management Journal, v.26, p.1087-1108, 2005.

LUMPKIN,G.T.; DESS,G.G..Clarifying the Entrepreneurial Orientation Construct and Linking it to Performance. Academy of Management Review vol.21, p.135-172, 1996. 
LUNDVALL, B; MADSEN, P.T.; KRISTENSEN, F.S. Increased Flexibility, Innovativeness and Human Resource Development as a Response to Increased Competition. Presented at the DRUID - seminar, January, 1997.

MALHOTRA, N.K. Pesquisa de Marketing: Uma orientação aplicada. (Marketing Research: An Applied Orientation) 3ed, Porto Alegre: Bookman, 2001.

MARUCHECK, A.; MCCLEALLAND, M. Planning Capacity Utilization in an Assemble-to-order Environment. International Journal of Operations \& Production Management. vol.12, p.18-38, 1992.

NOHRIA, N.; GULATI, R. Is slack Good or Bad for Innovation? Academy of Management Journal, vol.39, p. 1245-1264, 1996.

PAVITT, K. Innovation Processes. In: FAGERBERG, J.; MOWERY, D.C.; NELSON, R.R. The Oxford Handbook of Innovation. Oxford: Oxford University Press, 2006.

PENROSE, E. A Teoria do Crescimento da Firma. (The Theory of the Growth of the Firm) Campinas, Unicamp, 2006. Based on the $3^{\text {rd }}$ ed in English from 1995.

PENROSE, Edith. Limits to the Growth and Size of Firms. The American Economic Review, vol. 45, p. 531-543, 1955.

PETERAF, Margaret A.. The Cornerstones of Competitive Advantage: A Resource-based View. Strategic Management Journal, vol. 14, p. 179-191, 1993.

PORTER, M.E. Estratégia Competitiva: Técnicas para análise de indústrias e da concorrência. (Competitive Strategy: Techniques for the analysis of industries and of the competition.) Rio de Janeiro: Campus, 7ed.,1986.

RONDE, P.; HUSSLER, C. Building Relational competences with Neighbours: Does it really enhance innovation? Paper presented at the DRUID Summer Conference, Industrial Dynamics, Innovation and Development, Elsinore/Denmark: June, 2004.

ROSNER, M.M. Economic Determinants of Organizational Innovation. Administrative Science Quarterly, vol 12, p. 614-625, 1968.

RUBIN, P. H. The Expansion of Firms. Journal of Political Economy, vol. 81, p. 936-949, 1973.
SAWHNEY, R. Interplay Between Uncertainty and Flexibility Across the Value-chain: Towards a transformation model of manufacturing flexibility. Journal of Operations Management, vol.24, p.476-493, 2006

SCHUMPETER, J. A. Teoria do Desenvolvimento Econômico: uma investigação sobre lucros, capital, crédito, juros e o ciclo econômico. (Theory of Economic Development: an investigation about the profits, capital, credit, interest and economic cycle.) São Paulo: April, 1982.

SHARFMAN, M.P.; WOLF, G; CHASE, R.B.; TANSIK, D.A. Antecedents of Organizational Slack. Academy of Management Review, vol.13, p.601-614, 1988 .

SMITH, K. Measuring Innovation. In: FAGERBERG, J.; MOWERY, D.C.; NELSON, R.R. The Oxford Handbook of Innovation. Oxford: Oxford University Press, 2006.

SOLO, C. S. Innovation in The Capitalist Process: A critique of the Schumpeterian Theory. Quarterly Journal of Economics. Wellesley College, 1951

TAN, J.; PENG, M.W. Organizational Slack and Firm Performance During Economic Transitions: Two studies from an emerging economy. Strategic Management Journal, vol.24, p.1249-1263, 2003.

TIDD, J.; BESSANT, J.; PAVITT, K. Managing Innovation: Integrating Technological, Market, and Organizational Change. Chichester, England: John Wiley \& Sons Ltd., 1997.

TIDD, J.; BESSANT, J.; PAVITT, K. Managing Innovation: Integrating Technological, Market, and Organizational Change. 3ed. Chichester, England: John Wiley \& Sons Ltd., 2005.

VOSS, G.B.; SIRDESHMUKH, D.; VOSS, Z.G. The Effects of Slack Resources and Environmental Threat on Product Exploration and Exploitation. Academy of Management Journal, vol. 51, p.147-164, 2008.

WERNERFELT, B. A Resource-based View of the Firm. Strategic Management Journal, vol. 5, p.171-180, 1984.

WORDNET. A Lexical Database for the English Language. Cognitive Science Laboratory, Princeton University. Available at http:// wordnet.princeton.edu//. Last access on Jan. 22, 2009.

\section{Author's Biography}

Júlio Francisco Blumetti Facó is PhD in Administration with Operations Management and Innovation emphasis. Professor at UFABC (Federal University of ABC region at São Paulo Metropolitan Area in Brazil). Researcher at Technology Innovation Dept at UFABC. Interests in Innovation, Organizational Innovativeness, Operations Management and SCM.

João Mario Csillag is Aeronautical Engineer, Master and PHD in Business Administration. Professor in Operations in FGV-EAESP. Consultant in Competitiveness, Quality, Supply Chain, Product Innovation. 